\title{
BODY IMAGE CONCERNS: LEVELS, CORRELATES AND GENDER DIFFERENCES AMONG STUDENTS IN THE UNITED KINGDOM
}

\author{
Walid El Ansari', Emily Dibba², Christiane Stock ${ }^{2}$ \\ ${ }^{1}$ Faculty of Applied Sciences, University of Gloucestershire, Gloucester, United Kingdom \\ 2Unit for Health Promotion Research, Institute of Public Health, University of Southern Denmark, Esbjerg, Denmark
}

\section{SUMMARY}

Aims: This cross-sectional study aimed to determine the socio-demographic, lifestyle and well-being variables that are associated with body image concerns $(B I C)$ and whether these associations differed between female and male students.

Methods: A cross-sectional survey; 3,706 undergraduate students (2,699 females, 765 males) from seven universities in the UK completed a self-administered questionnaire that assessed socio-demographic, lifestyle, well-being and BIC based on the Body Shape Questionnaire developed by Cooper et al. Multifactorial logistic regression analysis examined the odds ratios for the association between four increasing levels of BIC as the dependent variables (no BIC, mild BIC, moderate BIC and marked BIC) on the one hand, and the socio-demographic (gender, age, year at university), lifestyle (physical activity, nutrition) and mental well-being variables (quality of life, perceived stress, perceived health, depressive symptoms) on the other.

Results: More females (35\%) than males (8\%) reported being moderately or markedly concerned with their body image. For both genders, $\mathrm{BIC}$ was associated with a higher level of depressive symptoms and to variable extents, with nutrition and year at university. Females' BICs were exclusively associated with low perceived health, higher perceived stress, studies in general as a stressor, and low physical activity. In contrast, males' BIC were found to be exclusively associated with low quality of life and with older age.

Conclusions: Health promoting strategies and activities should address the co-occurrence of depressive symptoms and BIC and should moreover pay attention to the gender-specific correlates of BIC for tailoring evidence based interventions for females and for males.

Key words: body image concern, gender, student's health, university, body shape, stress, depressive symptoms

Address for correspondence: W. El Ansari, Faculty of Applied Sciences, University of Gloucestershire, Oxstalls Campus, Oxstalls Lane, Gloucester GL2 9HW, United Kingdom. E-mail: walidansari@glos.ac.uk.

\section{INTRODUCTION}

Body image is the mental image we have of the size, shape and contour of our own bodies as well as of our feelings about these characteristics and the parts that constitute our bodies (1, 2). It is defined as the way a person perceives or thinks about his body and how it appears to others (3). The literature suggests that body image perceptions and concerns are important for university students, probably because of the increasing popularity of achieving or maintaining a healthy weight and appearance (4).

For instance, in Spain, more than half a sample of college students (55\% of women, $63 \%$ of men) had a distorted judgment of their body (5). Similarly, research across undergraduate college students in Austria, France and USA observed a wide discrepancy between men's actual muscularity and their body ideals (6). Likewise, university students in Denmark and the UK perceived themselves as either 'too thin' or 'too fat' (7). In Lebanon, $19 \%, 12 \%$ and $5 \%$ of students were either slightly, moderate or extremely worried, respectively, about their body image perception (4).

Such body image concerns (BIC) and body shape perceptions have many implications. Among Dutch adolescents, feeling overweight, rather than being overweight, appeared to be important (8). Body checking and avoidance have also been described as 'not benign' behaviours among female college students (9). Further, discrepancies between actual body shape and preferred body ideals may help explain anabolic steroid abuse among university males (6). Indeed, the correlates and consequences of negative body talk among men appear as serious as those of women (10). Equally, current smoking among college students is related to intention to lose weight (11). In addition, there may be also Appearance-based Rejection Sensitivity (Appearance-RS) (dispositional tendency to anxiously expect, readily perceive, and overreact to signs of rejection based on one's physical appearance) (12). For instance, American college students with relatively high Appearance-RS were more likely to negatively interpret/evade social circumstances that emphasize their physical appearance (12). Given such potential effects, social comparison behaviour and achieving a hoped-for thin self highlight the importance of BIC (their levels, correlates and gender differences). Certainly BIC has repercussions for the well-being of young adults attending college (13).

Generally BIC is associated with a complex range of factors to include socio-demographic variables e.g. gender (14), age and year of university study. BIC is also associated with physical activity (PA) (15), nutrition behaviours (16), and mental well-being, e.g., quality of life (QoL), perceived stress, perceived health, and depressive symptoms $(7,17)$. 
Nevertheless, the literature suggested several gaps in the knowledge base. First, BIC studies focused particularly on females (9). BIC studies in men are more limited, even though many men suffer from conditions characterized by altered body perceptions (18). Second, research employed limited sample sizes, mainly collected within one or two higher education institutions $(9,14$, 19). Third, single-country body image studies from more than one university seem not to compare universities (19). Fourth, research of BICs and associated variables focused on e.g. mass media or social influences (20). Few studies examined the relationships between BIC and a range of variables to include socio-demographic features, lifestyle characteristics, and mental well-being. The current study bridges these knowledge gaps.

We examined the relationships between four levels of BIC and a range of (ten) associated variables to include three socio-demographic features (gender, age, year at university), two lifestyle aspects (PA, nutrition), and five mental well-being characteristics (QoL, stress due to studies, perceived stress, self rated health, depressive symptoms). The research included undergraduate students (four academic levels) across seven universities in three countries of the UK. We compared all the variables by university and by gender. We then assessed the correlates of each of the four BIC levels (dependent variable) employing socio-demographic, lifestyle, and mental well-being features (independent variables) for the whole sample and by gender; and contrasted the emerging correlates by gender. The three specific objectives were to:

- describe the prevalence of BIC and potentially associated variables by seven universities;

- describe differences in the prevalence of BIC and potentially associated variables between males and females; and,

- assess the correlates of each of the four increasing levels of $\mathrm{BIC}$ for the whole sample and contrast the correlates by gender.

\section{MATERIALS AND METHODS}

\section{Sample}

The present study comprised data from a sample of 3,706 undergraduate students from the UK collected during the academic year 2007-2008. Data were collected at seven universities in England: University of Chester $(\mathrm{N}=993, \mathrm{M}$ age 26.0 years, $\mathrm{SD}$ 9.2), University of Gloucestershire ( $\mathrm{N}=970, \mathrm{M}$ age 23.3 years, SD 8.4 years), Plymouth University ( $\mathrm{N}=169$, M age 24.6, SD 7.2), Oxford Brookes University ( $\mathrm{N}=208, \mathrm{M}$ age 31.6, SD 10.4), Bath Spa University ( $\mathrm{N}=485, \mathrm{M}$ age 22.2, SD 6.9); Northern Ireland: University of Ulster $(\mathrm{N}=474, \mathrm{M}$ age 25.2, $\mathrm{SD} 7.7)$; and Wales: University of Swansea ( $\mathrm{N}=406, \mathrm{M}$ age 25.0, SD 7.4). The response rate was $\approx 80 \%$ (i.e. $80 \%$ of the questionnaires that were distributed to students were completed and returned to the research team).

\section{Data Collection}

The participating institutions' ethics and research committees approved the study. Courses adequately representing the different departments/faculties at the participating universities were selected, and students were invited to participate. Students attending the selected class/course were provided with self-administered questionnaires, which were then collected after completion. By completing and submitting the voluntary/anonymous questionnaire, students agreed to participate in the study. No incentives were provided to students for participation. Data were confidential and protected. All data were computer-entered centrally at one site thus minimizing potential data entry errors.

\section{Student Health Questionnaire}

The questionnaire was a general student health survey implemented at universities in the UK and other countries (7, 21-23). It collected information about body image perception, socio-demographic factors (e.g., gender, age), year of study at university, lifestyle characteristics (e.g., PA, nutrition behaviour) and mental well-being (e.g., QoL, perceived stress, perceived health, depression symptoms).

Body Image Concerns (8 items): was assessed based on the Body Shape Questionnaire (24) measuring levels of concern with shape in the last 4 weeks (six-point Likert scale, $1=$ 'Never' to $6=$ 'Always'). The items covered symptoms that can appear regarding a negative body image perception. Sample items include: "Have you been so worried about your shape that you have been feeling you ought to diet?"; "Have you noticed the shape of others and felt that your own shape compared unfavourable?". The total score of the Body Shape Questionnaire ranged from 8 to 48 points. Cronbach's alpha for the scale was 0.93 . We categorized the score into four levels (24): 'No' BIC (8-18 points); 'Mild' BIC (19-25 points); 'Moderate' BIC (26-33 points); or 'Marked' BIC (34-48 points).

Year at University (1 item): Participants were classified in four groups: 1st (first year at university), 2nd (second year at university), 3 rd (third year at university), $\geq 4$ th (fourth and fifth year at university, and other).

Physical Activity (PA)(2 items): measured using the American Heart Association (AHA) guidelines (25). We computed PA by combining participants' responses to two questions: "On how many of the past 7 days did you participate in moderate exercise for $\geq 30$ minutes?", and "On how many of the past 7 days did you participate in vigorous exercise for $\geq 20$ minutes?". Participants answered from 0 to 7 days to both questions. We then computed low PA: 'Yes' if 0 days of $\geq 20$ minutes vigorous exercise, or $\leq 1$ days of $\geq 30$ minutes moderate exercise; and 'No' if $\geq 1$ days of $\geq 20$ minutes vigorous exercise, or $>1$ day of $\geq 30$ minutes moderate exercise, in agreement with others $(22,26)$.

Nutrition (4 items): Students completed a food frequency questionnaire (4 indicator variables) that measured their consumption of sweets, cakes/cookies, snacks and fast/canned food. The introductory question, "How often do you eat the following foods?" asked participants about the frequency of participants' usual consumption of each food group separately (rated on a 5-point scale: several times a day -5 points, daily -4 points, several times a week -3 points, $1-4$ times a month -2 points, and never - 1 point). Using these points, all food items were then used to construct a total score labeled: 'high calorie diet score' (rang: $4-20$ points). For the current analysis, using tertiles, the scores were separated in: 'Low' $=1$ st tertile, 'Medium' $=2$ nd tertile, and 'High' high calorie diet score $=3$ rd tertile.

Quality of Life (QoL) (1 item): "If you consider the quality of your life: How did things go for you in the last four weeks?" (27). 
Response ratings ranged from: 'Very badly' (5 points); 'Badly' (4 points); 'Intermediate' (3 points); 'Quite well' ( 2 points); or 'Very well' ( 1 point). For the current analysis, the options were re-coded into two categories: 'Lower' ('very badly', 'badly' or 'intermediate'); and 'Higher' QoL ('quite well' or 'very well').

Stressors (1 item): "To what extent do you feel burned out in the following area(s)?": Studies in general, rated on a six-point Likert scale from 'Not at all' (1 point) to 'Very strongly' (6 points). We created a binary variable by dividing the Likert scale into two groups ('Lower' and 'Higher' stress levels) using median split.

Perceived stress (4 items): measured with the 4-item Perceived Stress Scale (PSS-4) (28), using a five-point Likert scale $(0=$ 'Never', 4 = 'Very often'). Employing a median split, the stress score (total sum ranging between $0-16$ points) was recoded in two categories: 'Below' median and 'Above' median.

Self-rated health (1 item): "How would you rate your health in general?", rated using a five-point scale: 'Excellent'; 'Very good'; 'Good'; 'Fair'; 'Poor', as consistent with other studies (29). For the current analysis, we re-coded the item into 2 categories: 'Higher' perceived health ('excellent' and 'very good') and 'Lower' perceived health ('good', 'fair' and 'poor').

Depressive symptoms ( 8 items): measured using the Modified Beck Depression Inventory (M-BDI) (30). The questionnaire included a single statement per symptom of depression with a six-point Likert scale measuring its frequency in the past few days, with the extreme categories labeled as $0=$ 'Never', $6=$ 'Almost Always'. We calculated the sum ( $0-48$ points) and categorized depressive symptoms into two groups ('Lower' and 'Higher' depressive symptoms) using a cut-off of $>5$ th quintile.

\section{Statistical Analysis}

SPSS 20.0 was used for the analyses. We calculated frequencies and proportions. For several variables, some of the response options were combined to satisfy the assumption of adequate cell size for regression analysis. In order to adjust for multiple comparisons, the significance level was set at $\mathrm{p}<0.005$.

For the first and second objectives, frequencies were reported by university and separately for females and males. Chi-square tests were computed in order to compare the frequencies of the levels of BIC and associated (socio-demographic, lifestyle, and mental well-being) variables by universities and by gender.

For objective three, four separate multifactorial logistic regression analysis (enter mode) examined the odds ratios for the association between the four increasing BIC levels as the dependent variables (no BIC; mild BIC; moderate BIC; marked BIC) corresponding with $8-18$ points, $19-25$ points, $26-33$ points, $34-48$ points, respectively, that represent the total score across the 8 items of the Body Shape Questionnaire (24) on the one hand, and the socio-demographic (gender, age, year at university) and lifestyle (PA, nutrition) and mental well-being variables (QoL, perceived stress, perceived health, depressive symptoms) on the other. This was undertaken for the whole sample and by gender. In the regression with 'no BIC' as outcome, all other higher BIC levels were used as reference group; with 'mild BIC' as outcome, the higher levels were the reference; with 'moderate BIC' as outcome, 'marked BIC' was the reference; and for 'marked BIC', all other lower levels of BIC were the reference. Results were expressed as odds ratios (OR) and 95\% confidence intervals (95\% CI).

\section{RESULTS}

\section{Frequency of Body Image Concern and Associated Variables by Seven Universities}

The BIC levels and the socio-demographic, lifestyle, and mental well-being variables differed by university (Table 1). For instance, Gloucestershire had the highest proportion $(\approx 64 \%)$ of no BIC; Ulster had the lowest (37\%). Conversely, Ulster had the highest proportion of marked BIC (18\%); Gloucestershire had the lowest $(8 \%)$. Further, across the sample, Ulster had a relatively high proportion of females (92\%), highest level of low PA (40\%), highest frequency of high calorie diet (46\%), lowest QoL (61\%), highest study-related stress (34\%), highest perceived stress (50\%), lowest level of perceived health $(55 \%)$, and highest prevalence of depressive symptoms (24\%). Conversely, Gloucestershire had the highest proportion of males (44\%), lowest level of low PA (17\%), lowest level of high calorie diet (32\%), highest QoL (68\%), lowest levels of study-related stress $(15 \%)$ and perceived stress (39\%), high level of perceived good health $(51 \%)$, and lowest level of depressive symptoms $>5$ th quintile $(15 \%)$. Females where more represented at most sites, probably due to the schools (e.g., Schools of Nursing, of Health Sciences, or of Health \& Social Care, etc.) at each university where the data were collected.

\section{Frequency of Body Image Concern and Associated Variables by Gender}

BIC was not evenly distributed by gender (Table 2). Only about $43 \%$ of females perceived no BIC; the remaining $57 \%$ expressed mild, moderate, or marked BIC. Conversely, approximately $80 \%$ of males had no BIC. Females differed significantly from males across several other variables, reporting higher proportions of e.g., low PA, low/medium high calorie diet, lower QoL, higher stress level due to studies in general, higher perceived stress, lower perceived health, and more depressive symptoms.

\section{Correlates of Four Levels of Body Image Concern for Whole Sample}

Multifactorial logistic regression indicated that females were less likely to report no $\mathrm{BIC}(\mathrm{OR}=0.18)$, and at greater risk of marked $\mathrm{BIC}(\mathrm{OR}=6.30)$ (females were 6.3 times more likely than males to report marked BIC) (Table 3). Some variables were associated with higher risk of marked BIC, e.g., higher perceived stress $(\mathrm{OR}=1.33)$ (students with higher perceived stress were 1.33 times more likely than those with lower perceived stress to have marked $\mathrm{BIC})$, lower perceived health $(\mathrm{OR}=1.79)$, depressive symptoms $(\mathrm{OR}=2.93)$, and low $\mathrm{PA}(\mathrm{OR}=1.36)$. Conversely, some and mostly the same variables were associated with a reduced likelihood of no BIC, e.g., higher perceived stress $(\mathrm{OR}=$ $0.61)$, lower perceived health $(\mathrm{OR}=0.62)$, depressive symptoms $(\mathrm{OR}=0.51)$, and higher stress level in studies in general $(\mathrm{OR}=$ 0.80 ). Besides gender, perceived stress and perceived health had significant associations with all four increasing BIC levels, which indicated a strong increasing association. Higher level of high calorie diet $(\mathrm{OR}=1.37)$ increased the risk of having moderate $\mathrm{BIC}$, while higher QoL decreased the risk $(\mathrm{OR}=0.75)$ of having marked BICs. 


\section{Correlates of Four Levels of Body Image Concern} among Female Students

Among females, multifactorial logistic regression indicated that two variables (perceived stress and perceived health) were significantly associated with all four BIC levels (Table 4). Some variables were associated with a higher risk of marked BIC, e.g., higher perceived stress $(\mathrm{OR}=1.38)$, lower perceived health $(\mathrm{OR}$ $=1.83)$, higher depressive symptoms $(\mathrm{OR}=2.73)$ (students with higher depressive symptoms were 2.73 times more likely than those with lower depressive symptoms to have marked BIC), and low PA (OR =1.34). Conversely, some and mostly the same variables were associated with a decreased risk of having no BIC, e.g., higher perceived stress $(\mathrm{OR}=0.56)$, lower perceived health $(\mathrm{OR}=0.59)$, higher depressive symptoms $(\mathrm{OR}=0.55)$, and higher stress level due to studies in general $(\mathrm{OR}=0.76)$. In addition to the variables perceived stress and perceived health, some variables were associated with an increased risk of moderate BIC, e.g., depressive symptoms $(\mathrm{OR}=1.77)$, and higher level of high calorie $\operatorname{diet}(\mathrm{OR}=1.38)$ (students consuming high calorie diet were 1.38 times more likely than those consuming low calorie diet to report moderate BIC).

\section{Correlates of Four Levels of Body Image Concern among Male Students}

Among males, the variables that were associated with no BIC were higher $\mathrm{QoL}(\mathrm{OR}=1.94)$ (i.e. students with higher $\mathrm{QoL}$ were 1.94 times more likely than lower QoL to report no BIC) and third year at university $(\mathrm{OR}=2.29)$, whereas depressive symptoms were negatively associated with having no BIC (Table 5). Conversely, males with depressive symptoms $(\mathrm{OR}=10.62)$ and $\geq 30$ years old $(\mathrm{OR}=1.84)$ were more likely to have marked BIC. A higher level of high calorie diet $(\mathrm{OR}=0.21)$ was negatively associated with marked BIC among males. Moderate BIC were more likely among those aged 21-29 $(\mathrm{OR}=4.21)$ and aged $\geq 30(\mathrm{OR}=5.29)$ as compared to younger students. Mild BIC was negatively associated with high $\mathrm{QoL}(\mathrm{OR}=0.54)$ and with third year at university $(\mathrm{OR}=0.31)$.

Table 6 summarizes the differences in correlates of the four BIC levels by gender (based on Tables 4 and 5). The associations of BIC with the different socio-demographic, lifestyle, and mental wellbeing variables differed by gender. For instance, some variables were more important for females, as these variables had significant associations with BIC exclusively among females (not among males), e.g., perceived stress and perceived health (at all levels of BIC), higher stress level due to studies (for no BIC), and low PA (for higher BIC). Conversely, some variables were more important for males, as these variables had significant associations with BIC exclusively among males (not among females), e.g. age and quality of life. In addition, other variables were important for both genders as these variables had significant (but few and scattered) associations with BIC among females and also among males, e.g. nutrition, year at university. Depressive symptoms were associated with more BIC levels for females than males.

\section{DISCUSSION}

This study assessed BIC levels, lifestyle factors, and mental well-being of students at seven UK universities, to provide data on BIC and associated lifestyle and mental well-being variables among UK university students.

\section{Prevalence of Body Image Concern and Associated Variables by Seven Universities}

In relation to the study's first objective, $51 \%$ of our sample had no BIC. However, we found higher proportions of students from Ulster reporting mild, moderate, or marked BIC. When comparing the seven participating universities across the lifestyle and mental well-being variables, in this instance, some universities (e.g. Ulster) had less favourable scores (high perceived stress, higher stress level due to studies in general, highest level of high calorie diet, high level of depressive symptoms, lower perceived health, low PA, and lower QoL). A point to consider is the high proportion of females in the Ulster sample (91.8\%), since there is a strong association between females and BIC (31). Conversely, in our sample, in this instance, some universities (e.g. Gloucestershire) scored more favourably, as only $8.2 \%$ of the participants reported marked BIC, and they seemed more physically active and had less depressive symptoms.

The current study observed such 'clustering' of favourable or less favourable characteristics and health practices as regards the participating universities' differences in BIC, lifestyle features and mental health. It is not easy to explain such differences. El Ansari $(7,22)$ suggested that differences between participating universities could be related to, e.g., university characteristics and its environment, policies, student selection procedures and resultant composition of the student population; the region where a university is located; or the country and its political and health stances. Hence the inter-university differences we found might be due to student-level and/or university-level features (22). Similar challenges were noted in appraising the relationships between student health outcomes and student- and school-level features (32). Unravelling such dimensions is a complicated process that needs further assessment, particularly as these dimensions relate to determinants of student health/well-being. Very few multi-level studies collected student- and university-level information to be able to advance our understandings of such relationships.

\section{Prevalence of Body Image Concern and Associated Variables by Gender}

For objective two, in agreement with others (31), we found a generally high BIC among females, whether it was mild, moderate or marked BIC. Others have reported that a proportion of female students $(<50 \%)$ where concerned with their body shape (33), and research found that $76.2 \%$, and $72.7 \%$ of Korean and Chinese students, respectively, wanted a thinner body shape (34).

In the current UK sample, $\approx 20 \%$ of males had BIC. The few studies that examined BIC among males show a BIC trend among males $(35,36)$. Concern with shape is different across genders; females were concerned with being too fat, and males were concerned with muscle size/tone (36).

We found that more females had BIC compared to males even after adjusting for other lifestyle and mental well-being variables. We agree with others, e.g. in India, more females had higher dissatisfaction with their current body shape (37). Further, we found that less female students had no BIC compared to males, 
Table 1. Levels of and variables potentially associated with body image concern by university

\begin{tabular}{|c|c|c|c|c|c|c|c|c|c|}
\hline \multirow[t]{2}{*}{ Variable } & $\begin{array}{l}\text { Chester } \\
(\mathrm{N}=993)\end{array}$ & $\begin{array}{c}\text { Glouces- } \\
\text { tershire } \\
(\mathrm{N}=970)\end{array}$ & $\begin{array}{c}\text { Ulster } \\
\text { (N=475) }\end{array}$ & $\begin{array}{l}\text { Swansea } \\
(\mathrm{N}=406)\end{array}$ & $\begin{array}{l}\text { Plymouth } \\
(\mathrm{N}=169)\end{array}$ & $\begin{array}{c}\text { Oxford } \\
\text { Brookes } \\
(\mathrm{N}=208)\end{array}$ & $\begin{array}{l}\text { Bath Spa } \\
(\mathrm{N}=485)\end{array}$ & \multirow[t]{2}{*}{$P$ value $^{\mathrm{a}}$} & Total \\
\hline & $n(\%)$ & $n(\%)$ & $n(\%)$ & $n(\%)$ & $n(\%)$ & $n(\%)$ & $\mathrm{n}(\%)$ & & $\mathrm{N}$ \\
\hline \multicolumn{10}{|l|}{ Body image perception } \\
\hline No concern & $360(45.0)$ & $540(63.9)$ & $167(37.3)$ & $165(45.0)$ & $102(62.6)$ & $81(51.3)$ & $222(51.5)$ & \multirow{4}{*}{$<0.001$} & 1,637 \\
\hline Mild concern & $168(21.0)$ & $151(17.9)$ & $110(24.6)$ & $70(19.1)$ & $32(19.6)$ & $30(19.0)$ & $92(21.3)$ & & 653 \\
\hline Moderate concern & $141(17.6)$ & $85(10.1)$ & $91(20.3)$ & $63(17.2)$ & $14(8.6)$ & $20(12.7)$ & $63(14.6)$ & & 477 \\
\hline Marked concern & $131(16.4)$ & $69(8.2)$ & $80(17.9)$ & $69(18.8)$ & $15(9.2)$ & $27(17.1)$ & $54(12.5)$ & & 445 \\
\hline \multicolumn{10}{|c|}{ Socio-demographic variables } \\
\hline \multicolumn{10}{|l|}{ Gender } \\
\hline Male & $114(13.1)$ & $396(43.6)$ & $38(8.2)$ & $31(7.8)$ & $61(36.1)$ & $21(10.8)$ & $104(22.6)$ & \multirow{2}{*}{$<0.001$} & 765 \\
\hline Female & $757(86.9)$ & $512(56.4)$ & $425(91.8)$ & $367(92.2)$ & $108(63.9)$ & $174(89.2)$ & $356(77.4)$ & & 2,699 \\
\hline \multicolumn{10}{|l|}{ Age (years) } \\
\hline $18-20$ & $410(43.7)$ & $505(55.3)$ & $148(32.0)$ & $154(39.1)$ & $58(34.5)$ & $37(18.7)$ & $269(58.6)$ & \multirow{3}{*}{$<0.001$} & 1,581 \\
\hline $21-29$ & $247(26.3)$ & $270(29.5)$ & $207(44.7)$ & $147(37.3)$ & 77 (45.8) & $58(29.3)$ & $149(32.5)$ & & 1,155 \\
\hline$\geq 30$ & $281(30.0)$ & $139(15.2)$ & $108(23.3)$ & $93(23.6)$ & $33(19.6)$ & $103(52.0)$ & $41(8.9)$ & & 798 \\
\hline \multicolumn{10}{|l|}{ Year at University } \\
\hline 1st & $552(61.6)$ & $311(34.5)$ & $104(22.5)$ & $190(47.7)$ & $32(18.9)$ & $45(22.4)$ & $257(54.1)$ & \multirow{4}{*}{$<0.001$} & 1,491 \\
\hline 2nd & $200(22.3)$ & $330(36.6)$ & $204(44.2)$ & $94(23.6)$ & $59(34.9)$ & $97(48.3)$ & $111(23.4)$ & & 1,095 \\
\hline $3 r d$ & $74(8.3)$ & $157(17.4)$ & $151(32.7)$ & $88(22.1)$ & 73 (43.2) & $6(3.0)$ & $106(22.3)$ & & 655 \\
\hline$\geq 4$ th & $70(7.8)$ & $104(11.5)$ & $3(0.6)$ & $26(6.5)$ & $5(3.0)$ & $53(26.4)$ & $1(0.2)$ & & 262 \\
\hline \multicolumn{10}{|c|}{ Lifestyle variables } \\
\hline \multicolumn{10}{|l|}{ Low PA } \\
\hline No & $556(70.6)$ & $739(83.5)$ & $238(59.8)$ & $300(76.5)$ & $141(83.4)$ & $162(83.1)$ & $392(84.3)$ & \multirow{2}{*}{$<0.001$} & 2,528 \\
\hline Yes & $232(29.4)$ & $146(16.5)$ & $160(40.2)$ & $92(23.5)$ & $28(16.6)$ & $33(16.9)$ & $73(15.7)$ & & 764 \\
\hline \multicolumn{10}{|c|}{ Nutrition (high calorie diet score) } \\
\hline Low & $310(35.3)$ & $326(37.0)$ & $104(23.5)$ & $135(34.6)$ & $88(52.4)$ & $92(46.0)$ & $117(39.2)$ & \multirow{3}{*}{$<0.001$} & 1,232 \\
\hline Medium & $286(32.6)$ & $271(30.8)$ & $135(30.5)$ & $128(32.8)$ & $42(25.0)$ & $59(29.5)$ & $139(30.8)$ & & 1,060 \\
\hline High & $282(32.1)$ & $283(32.2)$ & $203(45.9)$ & $127(32.6)$ & $38(22.6)$ & $49(24.5)$ & $136(30.1)$ & & 1,118 \\
\hline \multicolumn{10}{|c|}{ Mental well-being variables } \\
\hline \multicolumn{10}{|l|}{ Quality of life } \\
\hline Lower & $356(39.3)$ & $300(31.9)$ & $183(39.4)$ & $129(32.3)$ & $66(39.1)$ & $62(30.8)$ & $163(34.4)$ & \multirow{2}{*}{0.004} & 1,259 \\
\hline Higher & $551(60.7)$ & $641(68.1)$ & $282(60.6)$ & $270(67.7)$ & $103(60.9)$ & $139(69.2)$ & $311(65.6)$ & & 2,297 \\
\hline \multicolumn{10}{|l|}{ Stressor (studies in general) } \\
\hline Lower stress level & $769(77.4)$ & $821(84.6)$ & $315(66.8)$ & $331(81.5)$ & $114(67.5)$ & $151(72.6)$ & $383(79.0)$ & \multirow{2}{*}{$<0.001$} & 2,884 \\
\hline Higher stress level & $224(22.6)$ & $149(15.4)$ & $160(33.7)$ & $75(18.5)$ & $55(32.5)$ & $57(27.4)$ & $102(21.0)$ & & 822 \\
\hline \multicolumn{10}{|l|}{ Perceived stress score } \\
\hline Below median & $489(55.3)$ & $561(60.8)$ & $235(50.4)$ & $229(57.4)$ & $88(52.1)$ & $110(55.3)$ & $258(54.9)$ & 0013 & 1,970 \\
\hline Above median & $395(44.7)$ & $362(39.2)$ & $231(49.6)$ & $170(42.6)$ & $81(47.9)$ & $89(44.7)$ & $212(45.1)$ & 0.010 & 1,540 \\
\hline Self-rated health & & & & & & & & & \\
\hline Higher perceived health & $423(45.9)$ & $484(51.1)$ & $212(44.8)$ & $195(48.6)$ & $92(54.4)$ & $100(49.3)$ & $200(41.8)$ & , & 1,706 \\
\hline Lower perceived health & $499(54.1)$ & $463(48.9)$ & $261(55.2)$ & $206(51.4)$ & 77 (45.6) & $103(50.7)$ & $279(58.2)$ & 0.000 & 1,888 \\
\hline Depressive symptoms & & & & & & & & & \\
\hline Lower & $827(83.3)$ & $829(85.5)$ & $361(76.0)$ & $346(85.2)$ & $135(79.9)$ & $172(82.7)$ & $380(78.4)$ & & 3,050 \\
\hline $\begin{array}{l}\text { Higher (M-BDI > 5th } \\
\text { quintile) }\end{array}$ & $166(16.7)$ & $141(14.5)$ & $114(24.0)$ & $60(14.8)$ & $34(20.1)$ & $36(17.3)$ & $105(21.6)$ & $<0.001$ & 656 \\
\hline
\end{tabular}

${ }^{a} \mathrm{X}^{2}$-test to compare seven Universities; all cell percentages are column percentages 
Table 2. Levels of and variables potentially associated with body image concern by gender

\begin{tabular}{|c|c|c|c|c|}
\hline \multirow{2}{*}{ Variable } & Male (N = 765) & Female ( $\mathrm{N}=2,699)$ & \multirow{2}{*}{ P value ${ }^{a}$} & Total \\
\hline & $n(\%)$ & $\mathrm{n}(\%)$ & & $\mathrm{n}(\%)$ \\
\hline \multicolumn{5}{|l|}{ Body image perception } \\
\hline No concern & $551(80.2)$ & $1,037(42.6)$ & \multirow{4}{*}{$<0.001$} & $1,637(51.0)$ \\
\hline Mild concern & $81(11.8)$ & $551(22.6)$ & & $653(20.3)$ \\
\hline Moderate concern & $35(5.1)$ & $433(17.8)$ & & $477(14.9)$ \\
\hline Marked concern & $20(2.9)$ & $415(17.0)$ & & $445(13.9)$ \\
\hline \multicolumn{5}{|c|}{ Socio-demographic variables } \\
\hline \multicolumn{5}{|l|}{ Age (year) } \\
\hline $18-20$ & $378(50.7)$ & $1,129(42.5)$ & \multirow{3}{*}{$<0.001$} & $1,581(44.7)$ \\
\hline $21-29$ & $265(35.5)$ & $848(31.9)$ & & $1,155(32.7)$ \\
\hline$\geq 30$ & $103(13.8)$ & $678(25.5)$ & & $798(22.6)$ \\
\hline \multicolumn{5}{|l|}{ Year at University } \\
\hline $1 \mathrm{st}$ & $304(40.9)$ & $1,113(42.5)$ & \multirow{4}{*}{0.548} & $1,491(42.6)$ \\
\hline 2nd & $242(32.5)$ & $820(31.1)$ & & $1,095(31.3)$ \\
\hline $3 r d$ & $148(19.9)$ & $481(18.4)$ & & $655(18.7)$ \\
\hline$\geq 4$ th & $50(6.7)$ & $202(7.7)$ & & $262(7.5)$ \\
\hline \multicolumn{5}{|c|}{ Lifestyle variables } \\
\hline \multicolumn{5}{|l|}{ Low PA } \\
\hline No & $602(83.8)$ & $1,813(74.6)$ & \multirow{2}{*}{$<0.001$} & $2,415(76.8)$ \\
\hline Yes & $116(16.2)$ & $618(25.4)$ & & $764(23.2)$ \\
\hline \multicolumn{5}{|l|}{ Nutrition (high calorie diet score) } \\
\hline Low & $355(36.1)$ & $930(36.4)$ & \multirow{3}{*}{0.165} & $1,232(36.1)$ \\
\hline Medium & $203(28.7)$ & $813(31.8)$ & & $1,060(31.1)$ \\
\hline High & $249(35.2)$ & $815(31.9)$ & & $1,118(32.8)$ \\
\hline \multicolumn{5}{|c|}{ Mental well-being variables } \\
\hline \multicolumn{5}{|l|}{ Quality of life } \\
\hline Lower & $237(31.6)$ & $965(36.4)$ & \multirow{2}{*}{0.016} & $1,259(35.4)$ \\
\hline Higher & $512(68.4)$ & $1,686(63.6)$ & & $2,297(64.6)$ \\
\hline \multicolumn{5}{|l|}{ Stressor (studies in general) } \\
\hline Lower stress level & $639(83.5)$ & $2,056(76.2)$ & \multirow{2}{*}{$<0.001$} & $2,695(77.8)$ \\
\hline Higher stress level & $126(16.5)$ & $643(23.8)$ & & $822(22.2)$ \\
\hline \multicolumn{5}{|l|}{ Perceived stress score } \\
\hline Low & $480(65.0)$ & $1,410(53.7)$ & \multirow{2}{*}{$<0.001$} & $1,970(56.1)$ \\
\hline High & $259(35.0)$ & $1,218(46.3)$ & & $1,540(43.9)$ \\
\hline \multicolumn{5}{|l|}{ Self-rated health } \\
\hline Higher perceived health & $392(52.1)$ & $1,232(46.4)$ & \multirow{2}{*}{0.005} & $1,624(47.6)$ \\
\hline Lower perceived health & $360(47.9)$ & $1,425(53.6)$ & & $1,785(52.4)$ \\
\hline \multicolumn{5}{|l|}{ Depressive symptoms } \\
\hline Lower & $664(86.8)$ & $2,167(80.3)$ & \multirow{2}{*}{$<0.001$} & $3,050(82.3)$ \\
\hline Higher (M-BDI > 5th quintile) & $101(13.2)$ & $532(19.7)$ & & $656(17.7)$ \\
\hline
\end{tabular}

${ }^{a} \mathrm{X}^{2}$-test to compare gender; all cell percentages are column percentages

in agreement with others (38). It could be that mass media (e.g. television and exposure to magazines that advertise dieting and weight loss) impact on females' BIC and influence females to prefer ultra-thin body sizes (39).

Besides BIC, other variables also showed gender differences. We found that females had higher perceived stress, in agreement with Jordanian study (40). However, whilst in Jordan perceived stress was measured using the Student-life Stress Inventory (41), the current research, employed PSS-4 (28). Interestingly, among adult women, there seem to be associations between low levels of psychological distress and weight stability, whereas weight increase seems associated with increased BIC (42). As for our 
Table 3. Correlates of four different levels of body image concern among all students

\begin{tabular}{|c|c|c|c|c|}
\hline \multirow{2}{*}{ Variable } & No concern & Mild concern & Moderate concern & Marked concern \\
\hline & $\mathrm{OR}^{\mathrm{a}}(95 \% \mathrm{Cl})$ & $\mathrm{OR}^{\mathrm{a}}(95 \% \mathrm{Cl})$ & $\mathrm{OR}^{\mathrm{a}}(95 \% \mathrm{Cl})$ & $\mathrm{OR}^{\mathrm{a}}(95 \% \mathrm{Cl})$ \\
\hline \multicolumn{5}{|l|}{ Gender } \\
\hline Male & 1.00 & 1.00 & 1.00 & 1.00 \\
\hline Female & $0.18(0.14-0.22)$ & $3.75(2.82-4.98)$ & $5.34(3.57-7.99)$ & $6.30(3.75-10.58)$ \\
\hline \multicolumn{5}{|l|}{ Age } \\
\hline 18-20 & 1.00 & 1.00 & 1.00 & 1.00 \\
\hline $21-29$ & $0.90(0.73-1.12)$ & $1.02(0.79-1.33)$ & $1.23(0.93-1.62)$ & $1.12(0.83-1.51)$ \\
\hline$\geq 30$ & $1.06(0.83-1.34)$ & $0.90(0.68-1.19)$ & $0.93(0.67-1.30)$ & $1.16(0.83-1.63)$ \\
\hline \multicolumn{5}{|l|}{ Year at University } \\
\hline 1 st & 1.00 & 1.00 & 1.00 & 1.00 \\
\hline 2nd & $1.12(0.92-1.37)$ & $1.01(0.80-1.30)$ & $0.93(0.71-1.22)$ & $0.67(0.50-0.89)$ \\
\hline $3 r d$ & $1.19(0.93-1.52)$ & $0.89(0.65-1.22)$ & $0.94(0.68-1.32)$ & $0.73(0.51-1.03)$ \\
\hline$\geq 4$ th & $1.08(0.74-1.58)$ & $1.05(0.65-1.68)$ & $0.89(0.53-1.52)$ & $0.77(0.45-1.31)$ \\
\hline \multicolumn{5}{|l|}{ Low PA } \\
\hline No & 1.00 & 1.00 & 1.00 & 1.00 \\
\hline Yes & $0.99(0.81-1.21)$ & $0.79(0.61-1.03)$ & $1.21(0.93-1.58)$ & $1.36(1.05-1.77)$ \\
\hline \multicolumn{5}{|c|}{ Nutrition (high calorie diet score) } \\
\hline Low & 1.00 & 1.00 & 1.00 & 1.00 \\
\hline Medium & $1.03(0.83-1.26)$ & $1.00(0.77-1.30)$ & $0.88(0.66-1.18)$ & $1.16(0.87-1.55)$ \\
\hline High & $0.90(0.73-1.11)$ & $1.04(0.79-1.35)$ & $1.37(1.04-1.80)$ & $0.85(0.63-1.15)$ \\
\hline \multicolumn{5}{|l|}{ Quality of life } \\
\hline Lower & 1.00 & 1.00 & 1.00 & 1.00 \\
\hline Higher & $1.16(0.96-1.42)$ & $0.90(0.70-1.17)$ & $0.99(0.76-1.29)$ & $0.75(0.570 .98)$ \\
\hline \multicolumn{5}{|l|}{ Stressor (studies in general) } \\
\hline Lower stress level & 1.00 & 1.00 & 1.00 & 1.00 \\
\hline Higher stress level & $0.80(0.64-0.99)$ & $1.25(0.95-1.64)$ & $1.04(0.78-1.38)$ & $1.31(0.99-1.73)$ \\
\hline \multicolumn{5}{|l|}{ Perceived stress score } \\
\hline Low & 1.00 & 1.00 & 1.00 & 1.00 \\
\hline High & $0.61(0.50-0.74)$ & $1.51(1.18-1.93)$ & $1.58(1.22-2.05)$ & $1.33(1.00-1.78)$ \\
\hline \multicolumn{5}{|l|}{ Self-rated health } \\
\hline Higher perceived health & 1.00 & 1.00 & 1.00 & 1.00 \\
\hline Lower perceived health & $0.62(0.52-0.74)$ & $1.48(1.19-1.84)$ & $1.30(1.03-1.64)$ & $1.79(1.38-2.32)$ \\
\hline \multicolumn{5}{|l|}{ Depressive symptoms } \\
\hline Lower & 1.00 & 1.00 & 1.00 & 1.00 \\
\hline $\begin{array}{l}\text { Higher (M-BDI > 5th } \\
\text { quintile) }\end{array}$ & $0.51(0.39-0.66)$ & $1.03(0.72-1.46)$ & $1.86(1.37-2.54)$ & $2.93(2.19-3.91)$ \\
\hline
\end{tabular}

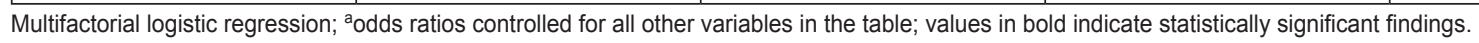

sample's PA, $\approx 25 \%$ (females) and 16\% (males) had low PA, which supports that low PA is more pronounced among females than males, in agreement with Malay study (31). Meeting PA guidelines might be effective in preventing obesity and other tendencies that could be a reason for BIC.

As for mental health, more females $(23.8 \%)$ than males (16.5\%) reported stress due to their studies. This is important, as females might use emotional and unhealthy eating behaviours to cope with the higher stress levels (43).
In terms of depressive symptoms, in the current study, more females $(19.7 \%)$ than males $(13.2 \%)$ reported depressive symptoms (M-BDI > 5th quintile), which have been observed to be related to body dissatisfaction (44). As for perceived health, more females $(53.6 \%)$ than males $(47.9 \%)$ had lower perceived health, which was better than the levels of university students from Egypt (23), but less favourable when compared to the USA (45). Students tend to have better perception of health when they have better body image satisfaction (46). 
Table 4. Correlates of four levels of body image concern among females

\begin{tabular}{|c|c|c|c|c|}
\hline \multirow{3}{*}{ Variable } & \multicolumn{4}{|c|}{ Females } \\
\hline & No concern & Mild concern & Moderate concern & Marked concern \\
\hline & $\mathrm{OR}^{\mathrm{a}}(95 \% \mathrm{Cl})$ & $\mathrm{OR}^{\mathrm{a}}(95 \% \mathrm{Cl})$ & $\mathrm{OR}^{\mathrm{a}}(95 \% \mathrm{Cl})$ & $\mathrm{OR}^{\mathrm{a}}(95 \% \mathrm{Cl})$ \\
\hline \multicolumn{5}{|l|}{ Age } \\
\hline $18-20$ & 1.00 & 1.00 & 1.00 & 1.00 \\
\hline $21-29$ & $0.97(0.77-1.21)$ & $0.95(0.71-1.27)$ & $1.09(0.81-1.46)$ & $1.20(0.89-1.62)$ \\
\hline$\geq 30$ & $1.14(0.88-1.47)$ & $0.84(0.60-1.17)$ & $0.83(0.59-1.17)$ & $1.17(0.83-1.65)$ \\
\hline \multicolumn{5}{|l|}{ Year at University } \\
\hline 1st & 1.00 & 1.00 & 1.00 & 1.00 \\
\hline $2 n d$ & $1.05(0.84-1.47)$ & $1.10(0.84-1.44)$ & $0.95(0.72-1.25)$ & $0.68(0.51-0.92)$ \\
\hline $3 r d$ & $1.04(0.79-1.37)$ & $1.07(0.76-1.51)$ & $0.96(0.68-1.37)$ & $0.75(0.52-1.07)$ \\
\hline$\geq 4$ th & $1.14(0.75-1.72)$ & $0.96(0.56-1.64)$ & $0.87(0.49-1.53)$ & $0.82(0.48-1.41)$ \\
\hline \multicolumn{5}{|l|}{ Low PA } \\
\hline No & 1.00 & 1.00 & 1.00 & 1.00 \\
\hline Yes & $0.97(0.78-1.21)$ & $0.79(0.59-1.05)$ & $1.22(0.93-1.60)$ & $1.34(1.03-1.76)$ \\
\hline \multicolumn{5}{|l|}{ Nutrition (high calorie diet score) } \\
\hline Low & 1.00 & 1.00 & 1.00 & 1.00 \\
\hline Medium & $1.01(0.82-1.27)$ & $1.01(0.76-1.33)$ & $0.87(0.64-1.19)$ & $1.17(0.87-1.58)$ \\
\hline High & $0.93(0.74-1.17)$ & $0.93(0.69-1.25)$ & $1.38(1.04-1.83)$ & $0.90(0.66-1.22)$ \\
\hline \multicolumn{5}{|l|}{ Quality of life } \\
\hline Lower & 1.00 & 1.00 & 1.00 & 1.00 \\
\hline Higher & $1.06(0.85-1.32)$ & $1.01(0.76-1.34)$ & $1.01(0.77-1.34)$ & $0.78(0.59-1.03)$ \\
\hline \multicolumn{5}{|l|}{ Stressor (studies in general) } \\
\hline Lower stress level & 1.00 & 1.00 & 1.00 & 1.00 \\
\hline Higher stress level & $0.76(0.60-0.97)$ & $1.29(0.96-1.74)$ & $1.09(0.81-1.46)$ & $1.31(0.99-1.74)$ \\
\hline \multicolumn{5}{|l|}{ Perceived stress score } \\
\hline Low & 1.00 & 1.00 & 1.00 & 1.00 \\
\hline High & $0.56(0.45-0.69)$ & $1.68(1.2-2.21)$ & $1.61(1.22-2.11)$ & $1.38(1.02-1.85)$ \\
\hline \multicolumn{5}{|l|}{ Self-rated health } \\
\hline Higher perceived health & 1.00 & 1.00 & 1.00 & 1.00 \\
\hline Lower perceived health & $0.59(0.49-0.71)$ & $1.54(1.21-2.00)$ & $1.29(1.01-1.65)$ & $1.83(1.40-2.39)$ \\
\hline \multicolumn{5}{|l|}{ Depressive symptoms } \\
\hline Lower & 1.00 & 1.00 & 1.00 & 1.00 \\
\hline Higher (M-BDI > 5th quintile) & $0.55(0.41-0.73)$ & $0.92(0.63-1.36)$ & $1.77(1.27-2.47)$ & $2.73(2.03-3.68)$ \\
\hline
\end{tabular}

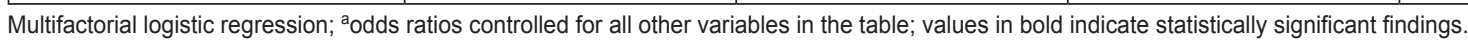

In terms of QoL, generally less females reported higher level of QoL compared to males (23), consistent with our findings, where about $68 \%$ (males) reported a higher level of high QoL (64\% females). The high QoL in the current study is close to that reported in Denmark (67.4\%) (7).

\section{Correlates of Four Levels of Body Image Concern across Seven Universities in the UK}

For objective three, besides gender (as discussed above), several variables were significantly associated with BIC even when the analysis was adjusted for the other variables under examination. We found that students with perceived poor health also had BIC. However, the cross-sectional design does not enable us to conclude any cause-effect relationships. Lower perceived health may increase the BIC levels; or alternatively, higher BIC levels may lead to decreased perceived health.

For perceived stress, our students who were stressed had greater risk of BIC. Stress is an increasingly reported problem, and is associated with unhealthy factors, e.g. disordered eating and mental well-being (47). In turn, disordered eating attitude is further negatively correlated with perceived desired body image among female students (47).

In relation to PA, being physically inactive is linked to overweight/obesity, which are not consistent with the thin female ideal body that is propagated by socio-cultural factors and mass media (48). 
Table 5. Correlates of four levels of body image concern among males

\begin{tabular}{|c|c|c|c|c|}
\hline \multirow{3}{*}{ Variable } & \multicolumn{4}{|c|}{ Males } \\
\hline & No concern & Mild concern & Moderate concern & Marked concern \\
\hline & $\mathrm{OR}^{\mathrm{a}}(95 \% \mathrm{Cl})$ & $\mathrm{OR}^{\mathrm{a}}(95 \% \mathrm{Cl})$ & $\mathrm{OR}^{\mathrm{a}}(95 \% \mathrm{Cl})$ & $\mathrm{OR}^{\mathrm{a}}(95 \% \mathrm{Cl})$ \\
\hline \multicolumn{5}{|l|}{ Age } \\
\hline $18-20$ & 1.00 & 1.00 & 1.00 & 1.00 \\
\hline $21-29$ & $0.72(0.43-1.20)$ & $1.19(0.64-2.23)$ & $4.21(1.51-11.69)$ & $0.25(0.05-1.27)$ \\
\hline$\geq 30$ & $0.53(0.27-1.05)$ & $1.30(0.54-3.13)$ & $5.29(1.55-18.11)$ & $1.84(0.42-8.05)$ \\
\hline \multicolumn{5}{|l|}{ Year at University } \\
\hline 1st & 1.00 & 1.00 & 1.00 & 1.00 \\
\hline 2nd & $1.49(0.89-2.50)$ & $0.72(0.40-1.32)$ & $0.84(0.31-2.31)$ & $0.52(0.14-1.90)$ \\
\hline $3 r d$ & $2.29(1.16-4.54)$ & $0.31(0.12-0.81)$ & $0.98(0.33-2.88)$ & $0.42(0.08-2.30)$ \\
\hline$\geq 4$ th & $0.66(0.27-1.61)$ & $1.86(0.65-5.33)$ & $1.38(0.31-6.09)$ & - \\
\hline \multicolumn{5}{|l|}{ Low PA } \\
\hline No & 1.00 & 1.00 & 1.00 & 1.00 \\
\hline Yes & $0.93(0.53-1.64)$ & $0.84(0.41-1.73)$ & $1.37(0.52-3.61)$ & $2.21(0.63-7.72)$ \\
\hline \multicolumn{5}{|l|}{ Nutrition (high calorie diet score) } \\
\hline Low & 1.00 & 1.00 & 1.00 & 1.00 \\
\hline Medium & $1.08(0.61-1.90)$ & $0.97(0.47-1.92)$ & $0.84(0.30-2.36)$ & $0.80(0.23-2.73)$ \\
\hline High & $0.76(0.45-1.29)$ & $1.71(0.90-3.25)$ & $1.17(0.45-3.02)$ & $0.21(0.04-0.97)$ \\
\hline \multicolumn{5}{|l|}{ Quality of life } \\
\hline Lower & 1.00 & 1.00 & 1.00 & 1.00 \\
\hline Higher & $1.94(1.19-3.16)$ & $0.54(0.30-0.97)$ & $0.70(0.29-1.71)$ & $0.37(0.10-1.35)$ \\
\hline \multicolumn{5}{|l|}{ Stressor (studies in general) } \\
\hline Lower stress level & 1.00 & 1.00 & 1.00 & 1.00 \\
\hline Higher stress level & $1.04(0.57-1.91)$ & $1.04(0.50-2.16)$ & $0.57(0.18-1.84)$ & $1.10(0.29-4.15)$ \\
\hline \multicolumn{5}{|l|}{ Perceived stress score } \\
\hline Below median & 1.00 & 1.00 & 1.00 & 1.00 \\
\hline Above median & $0.99(0.61-1.63)$ & $0.97(0.52-1.79)$ & $1.35(0.55-3.32)$ & $0.65(0.19-2.30)$ \\
\hline \multicolumn{5}{|l|}{ Self-rated health } \\
\hline Higher perceived health & 1.00 & 1.00 & 1.00 & 1.00 \\
\hline Lower perceived health & $0.75(0.47-1.18)$ & $1.29(0.74-2.27)$ & $1.53(0.63-3.69)$ & $1.27(0.40-4.05)$ \\
\hline \multicolumn{5}{|l|}{ Depressive symptoms } \\
\hline Lower & 1.00 & 1.00 & 1.00 & 1.00 \\
\hline Higher (M-BDI > 5th quintile) & $0.38(0.21-0.69)$ & $1.64(0.75-3.44)$ & $2.78(0.99-7.81)$ & $10.62(2.74-41.06)$ \\
\hline
\end{tabular}

Multifactorial logistic regression; ${ }^{a}$ odds ratios controlled for all other variables in the table; values in bold indicate statistically significant findings.

In connection with depressive symptoms, we found an increasing association between depressive symptoms and BIC level, for the whole sample (Table 3), among females (Table 4) (except for mild BIC - not significant), and also among males (Table 5) (except for mild and moderate BIC - both not significant). Others found depression to be associated with body dissatisfaction among students (37). Furthermore, the current study showed that those with depressive symptoms also seem more likely to have BIC.

The lifestyle variables of the current study (physical inactivity, high calorie diet) were associated with either moderate (as regards higher level of high calorie diet) or marked (as regards being low PA) BIC. Both lifestyle behaviours are considered unhealthy (49), and may lead to actually being overweight or high blood pressure that could result in not achieving the ideal thin body image that females might wish.

\section{Correlates of Body Image Concern among Female and Male Students}

For the third objective, depressive symptoms were critical for both genders at many BIC levels. We also found a highly significant association between depressive symptoms and marked BIC among males. Depression is a main mental health disorder (50) associated with other well-being variables, e.g. poor body image and lower self-esteem (50). In the current study, for both genders, those with depressive symptoms were at higher risk of BIC. 
Table 6. Correlates of four levels of body image concern: differences by gender

\begin{tabular}{|c|c|c|c|c|c|c|c|c|}
\hline & \multicolumn{8}{|c|}{ Level of Body Image Concern (BIC) } \\
\hline & \multicolumn{4}{|c|}{ Female } & \multicolumn{4}{|c|}{ Male } \\
\hline & $\begin{array}{l}\text { No } \\
\text { BIC }\end{array}$ & $\begin{array}{l}\text { Mild } \\
\text { BIC }\end{array}$ & $\begin{array}{l}\text { Moderate } \\
\text { BIC }\end{array}$ & $\begin{array}{l}\text { Marked } \\
\text { BIC }\end{array}$ & $\begin{array}{l}\text { No } \\
\text { BIC }\end{array}$ & $\begin{array}{l}\text { Mild } \\
\text { BIC }\end{array}$ & $\begin{array}{l}\text { Moderate } \\
\text { BIC }\end{array}$ & $\begin{array}{l}\text { Marked } \\
\text { BIC }\end{array}$ \\
\hline Age & - & - & - & - & - & - & Older $^{a}>$ younger $^{b}$ & Older $^{c}<$ younger $^{b}$ \\
\hline Year at University & - & - & - & 2 nd $<1$ st & $3 \mathrm{rd}>1 \mathrm{st}$ & $3 \mathrm{rd}<1 \mathrm{st}$ & - & - \\
\hline Physical activity & - & - & - & Yes $>$ no & - & - & - & - \\
\hline Nutrition score & - & - & High $>$ low & - & - & - & - & High $<$ low \\
\hline Quality of life & - & - & - & - & High $>$ low & Low $>$ high & - & - \\
\hline Stressor (studies) & High $<$ low & - & - & - & - & - & - & - \\
\hline Perceived stress & High $<$ low & High $>$ low & High $>$ low & High > low & - & - & - & - \\
\hline Perceived health & Low $<$ high & Low $>$ high & Low $>$ high & Low $>$ high & - & - & - & - \\
\hline Depressive symptoms & High $<$ low & - & High > low & High > low & High $<$ low & - & - & High > low \\
\hline
\end{tabular}

- no significant association; < and > indicate whether a given group is significantly less or more likely to report the given BIC; ${ }^{21}$ or older [both groups (21-29) and (30 or older) together]; ${ }^{b}(18-20) ;{ }^{c} 30$ or older; associations were significant at (at least) $\mathrm{P} \leq 0.05$

For both genders, nutrition behaviour was associated with BIC. A higher level of high calorie diet among females increased the risk of moderate BIC. Conversely, males with higher levels of high calorie diet had less marked BIC compared to those with a lower level of high calorie diet. Unhealthy eating behaviours among females could be due to e.g. coping with stress (51). Unhealthy eating habits could be difficult to change (63), and in our sample, even though those males with higher level of high calorie diet had less marked BIC, they could still be at risk of illness (diabetes, hypertension) and premature death (52).

The findings of the current UK sample indicated that some variables (perceived health, perceived stress, PA, and university study as a general stressor) were associated with BIC exclusively among females. By the same token, other variables (QoL, age) were associated with BIC exclusively among males. Such 'gender separation' of the type of variables that are critical to BIC for males and for females is important when planning prevention/ intervention strategies for body image and BIC.

As regards females, lower perceived health might actually be associated with less healthy habits, e.g. being less physically active (53). Low PA or inactivity higher the risk of gaining an unfavourable overweight body shape.

Less research examined males' BIC, attaching importance to the findings of the current study. For males, perceived QoL was partly associated with BIC. Males were more likely to have no BIC when reporting a higher QoL; and, males with mild BIC were less likely to perceive a higher QoL. We also found a highly significant association between males $\geq 21$ years old and a higher risk of moderate $\mathrm{BIC}$; whereas males $\geq 30$ years old were less likely to have marked BIC when compared with younger (18-20 years old) students (Tables 5, 6).

This study has limitations. As a cross-sectional survey, the directions of effects cannot be ascertained. Our sample remains a convenience sample (22). Self-reports might include recall bias and social desirability. Students who participated might be those with better physical/mental health. Therefore, the sample's BIC level might underestimate BIC across wider student populations. We assessed some variables by single items (survey conducted within a short time in classes, rendering use of in depth measures for each health factor unfeasible). BIC was measured by the Body Image Questionnaire (24) comprising questions originally developed based on women's BIC and hence might not be adequate to measure men's BIC. Concerns are more typical for men might be lacking from the questionnaire, which could underestimate men's actual BIC. Future research should try to address these limitations.

\section{CONCLUSION}

An overall conclusion from this UK study is that students' level of BIC differed by university and by gender. We found that whilst some variables were common and important to both genders' BIC; other variables were exclusively associated with BIC either for males or for females. Hence in addition to nutrition, year at university, and depressive symptoms which were common to both genders, preventive strategies and activities should further pay attention to the association of BIC with gender-specific variables, e.g., between higher perceived stress, low perceived health, low PA and BIC among females; and to the association between quality of life, older age and BIC among males.

Universities with more vulnerable student populations, e.g. more clustering of unhealthy habits might be more in need of comprehensive health promotion programmes. Whilst this study showed a relatively higher proportion of females with BIC, the special characteristics of males' BIC still need more attention and require the development of methods for specifically assessing male BIC.

\section{Acknowledgement}

The authors wish to acknowledge the universities, faculties and students who participated in this study. In addition, we wish to acknowledge the UK Student Health Group (J. John, P. Deeny, C. Phillips, S. Snelgrove, H. Adetunji, X. Hu, S. Parke, M. Stoate, and A. Mabhala).

\section{Conflict of Interest}

None declared 


\section{REFERENCES}

1. Slade PD. Body image in anorexia nervosa. Br J Psychiatry Suppl. 1988 Jul;(2):20-2.

2. Slade PD. What is body image? Behav Res Ther. 1994 Jun;32(5):497-502.

3. Khor GL, Zalilah MS, Phan YY, Ang M, Maznah B, Norimah AK. Perceptions of body image among Malaysian male and female adolescents. Singapore Med J. 2009 Mar;50(3):303-11.

4. Yahia N, El-Ghazale H, Achkar A, Rizk S. Dieting practices and body image perception among Lebanese university students. Asia Pac J Clin Nutr. 2011;20(1):21-8.

5. Míguez Bernárdez M, De la Montaña Miguélez J, González Carnero J, González Rodríguez M. Agreement between the self-perception on the body image and the nutritional status in college students from Orense. Nutr Hosp. 2011 May-Jun;26(3):472-9. (In Spanish.)

6. Pope HG Jr, Gruber AJ, Mangweth B, Bureau B, deCol C, Jouvent R, et al. Body image perception among men in three countries. Am J Psychiatry. 2000 Aug;157(8):1297-301.

7. El Ansari W, Clausen SV, Mabhala A, Stock C. How do I look? Body image perceptions among university students from England and Denmark. Int J Environ Res Public Health. 2010 Feb;7(2):583-95.

8. Jansen W, van de Looij-Jansen PM, de Wilde EJ, Brug J. Feeling fat rather than being fat may be associated with psychological well-being in young Dutch adolescents. J Adolesc Health. 2008 Feb;42(2):128-36.

9. White EK, Warren CS. Body checking and avoidance in ethnically diverse female college students. Body Image. 2013 Sep;10(4):583-90.

10. Engeln R, Sladek MR, Waldron H. Body talk among college men: content, correlates, and effects. Body Image. 2013 Jun;10(3):300-8.

11. Carroll SL, Lee RE, Kaur H, Harris KJ, Strother ML, Huang TT. Smoking, weight loss intention and obesity-promoting behaviors in college students. J Am Coll Nutr. 2006 Aug;25(4):348-53.

12. Park LE. Appearance-based rejection sensitivity: implications for mental and physical health, affect, and motivation. Pers Soc Psychol Bull. 2007 Apr;33(4):490-504.

13. Cho JH, Han SN, Kim JH, Lee HM. Body image distortion in fifth and sixth grade students may lead to stress, depression, and undesirable dieting behavior. Nutr Res Pract. 2012 Apr;6(2):175-81.

14. Di Pietro M, Silveira DX. Internal validity, dimensionality and performance of the Body Shape Questionnaire in a group of Brazilian college students. Rev Bras Psiquiatr. 2009 Mar;31(1):21-4.

15. Kirkcaldy BD, Shephard RJ, Siefen RG. The relationship between physical activity and self-image and problem behaviour among adolescents. Soc Psychiatry Psychiatr Epidemiol. 2002 Nov;37(11):544-50.

16. Brener ND, Eaton DK, Lowry R, McManus T. The association between weight perception and BMI among high school students. Obes Res. 2004 Nov;12(11):1866-74.

17. Kjaerbye-Thygesen A, Munk C, Ottesen B, Krüger Kjaer S. Why do slim women consider themselves too heavy? A characterization of adult women considering their body weight as too heavy. Int J Eat Disord. 2004 Apr;35(3):275-85.

18. Olivardia R, Pope HG Jr, Mangweth B, Hudson JI. Eating disorders in college men. Am J Psychiatry. 1995 Sep;152(9):1279-85.

19. Rø O, Reas DL, Lask B. Norms for the Eating Disorder Examination Questionnaire among female university students in Norway. Nord J Psychiatry. 2010 Dec;64(6):428-32.

20. Luevorasirikul K, Boardman H, Anderson C. An investigation of body image concern and the effects of sociocultural factors among U.K. first year university students. Public Health. 2012 Apr;126(4):365-7.

21. El Ansari W, Maxwell AE, Mikolajczyk RT, Stock C, Naydenova V, Krämer A. Promoting public health: benefits and challenges of a Europeanwide research consortium on student health. Cent Eur J Public Health. 2007 Jun; 15(2):58-65.

22. El Ansari W, Stock C, Phillips C, Mabhala A, Stoate M, Adetunji H, et al. Does the association between depressive symptomatology and physical activity depend on body image perception? A survey of students from seven universities in the UK. Int J Environ Res Public Health. 2011 Feb;8(2):281-99.

23. El Ansari W, Labeeb S, Moseley L, Kotb S, El-Houfy A. Physical and psychological well-being of university students: survey of eleven faculties in Egypt. Int J Prev Med. 2013 Mar;4(3):293-310.

24. PSYCTC. Body shape questionnaire (BSQ) and its shortened forms [Internet]. PSYCTC; 2011 [cited 2014 Apr 15]. Available from: http:// www.psyctc.org/tools/bsq/.

25. Haskell WL, Lee IM, Pate RR, Powell KE, Blair SN, Franklin BA, et al.; American College of Sports Medicine; American Heart Association.
Physical activity and public health: updated recommendation for adults from the American College of Sports Medicine and the American Heart Association. Circulation. 2007 Aug 28;116(9):1081-93.

26. Seo DC, Nehl E, Agley J, Ma SM. Relations between physical activity and behavioral and perceptual correlates among midwestern college students. J Am Coll Health. 2007 Sep-Oct;56(2):187-97.

27. Bruusgaard D, Nessiøy I, Rutle O, Furuseth K, Natvig B. Measuring functional status in a population survey. The Dartmouth COOP functional health assessment charts/WONCA used in an epidemiological study. Fam Pract. 1993 Jun;10(2):212-8.

28. Cohen S, Kamarck T, Mermelstein R. A global measure of perceived stress. J Health Soc Behav. 1983 Dec;24(4):385-96.

29. American College Health Association. American College Health Association National College Health Assessment (ACHA-NCHA) Spring 2005 Reference Group Data Report (abridged). J Am Coll Health. 2006 Jul-Aug;55(1):5-16.

30. Beck AT, Steer RA, Ball R, Ranieri W. Comparison of Beck Depression Inventories -IA and -II in psychiatric outpatients. J Pers Assess. 1996 Dec;67(3):588-97.

31. Pon LW Jr, Kandiah M, Mohd Nasir MT. Body image perception, dietary practices and physical activity of overweight and normal weight Malaysian female adolescents. Malays J Nutr. 2004 Sep;10(2):131-47.

32. Saab H, Klinger D. School differences in adolescent health and wellbeing: findings from the Canadian Health Behaviour in School-aged Children Study. Soc Sci Med. 2010 Mar;70(6):850-8.

33. Williamson DF, Serdula MK, Anda RF, Levy A, Byers T. Weight loss attempts in adults: goals, duration, and rate of weight loss. Am J Public Health. 1992 Sep;82(9):1251-7.

34. Ro Y, Hyun W. Comparative study on body shape satisfaction and body weight control between Korean and Chinese female high school students. Nutr Res Pract. 2012 Aug;6(4):334-9.

35. Furnham A, Badmin N, Sneade I. Body image dissatisfaction: gender differences in eating attitudes, self-esteem, and reasons for exercise. $\mathrm{J}$ Psychol. 2002 Nov;136(6):581-96.

36. Liao Y, Knoesen NP, Castle DJ, Tang J, Deng Y, Bookun R, et al. Symptoms of disordered eating, body shape, and mood concerns in male and female Chinese medical students. Compr Psychiatry. 2010 Sep-Oct;51(5):516-23.

37. Nichols SD, Dookeran SS, Ragbir KK, Dalrymple N. Body image perception and the risk of unhealthy behaviours among university students. West Indian Med J. 2009 Nov;58(5):465-71.

38. Thompson JK, Heinberg LJ, Altabe MN, Tantleef-Dunn S. Theory assessment, and treatment of body image disturbance. In: Thomson JK, Heinberg LJ, Altabe MN, Tantlee-Dunn. Exacting beauty: theory, assessment, and treatment of body image disturbance. Washington, DC: American Psychological Association; 1999.

39. Madanat HN, Brown RB, Hawks SR. The impact of body mass index and Western advertising and media on eating style, body image and nutrition transition among Jordanian women. Public Health Nutr. 2007 Oct;10(10):1039-46.

40. Hamaideh SH. Gender differences in stressors and reactions to stressors among Jordanian university students. Int J Soc Psychiatry. 2012 Jan;58(1):26-33.

41. Gadzella BM. Student-Life Stress Inventory: identification of and reactions to stressors. Psychol Rep. 1994 Apr;74(2):395-402.

42. Darby A, Hay P, Quirk F, Mond J, Buettner PG, Paxton SJ, et al. Better psychological health is associated with weight stability in women with eating disorders. Eat Weight Disord. 2009 Mar;14(1):13-22.

43. Hamilton S, Fagot BI. Chronic stress and coping styles: a comparison of male and female undergraduates. J Pers Soc Psychol. 1988 Nov;55(5):819-23.

44. Schulte SJ, Thomas J. Relationship between eating pathology, body dissatisfaction and depressive symptoms among male and female adolescents in the United Arab Emirates. Eat Behav. 2013 Apr;14(2):157-60.

45. American College Health Association. American College Health Association - National College Health Assessment Spring 2008 Reference Group Data Report (abridged). J Am Coll Health. 2009 Mar-Apr;57(5):477-88.

46. Kim MJ, Lim YR, Kwak HK. Dietary behaviors and body image recognition of college students according to the self-rated health condition. Nutr Res Pract. 2008 Summer;2(2):107-13.

47. Costarelli V, Patsai A. Academic examination stress increases disordered eating symptomatology in female university students. Eat Weight Disord. 2012 Sep; 17(3):e164-9.

48. Sypeck MF, Gray JJ, Ahrens AH. No longer just a pretty face: fashion magazines' depictions of ideal female beauty from 1959 to 1999 . Int J Eat Disord. 2004 Nov;36(3):342-7. 
49. Shimbo D, Levitan EB, Booth JN 3rd, Calhoun DA, Judd SE, Lackland DT, et al. The contributions of unhealthy lifestyle factors toapparent resistant hypertension: findings from the Reasons for Geographic And Racial Differences in Stroke (REGARDS) study. J Hypertens. 2013 Feb;31(2):370-6

50. Santos M, Richards CS, Bleckley MK. Comorbidity between depression and disordered eating in adolescents. Eat Behav. 2007 Dec;8(4):440-9.

51. Hou F, Xu S, Zhao Y, Lu Q, Zhang S, Zu P, et al. Effects of emotional symptoms and life stress on eating behaviors among adolescents. Appetite. 2013 Sep;68:63-8.
52. Campbell NR, Leiter LA, Larochelle P, Tobe S, Chockalingam A, Ward R, et al. Hypertension in diabetes: a call to action. Can J Cardiol. 2009 May;25(5):299-302.

53. Spein AR, Pedersen CP, Silviken AC, Melhus M, Kvernmo SE, Bjerregaard P. Self-rated health among Greenlandic Inuit and Norwegian Sami adolescents: associated risk and protective correlates. Int J Circumpolar Health. 2013 Feb;72:19793.

Received July 31, 2013

Accepted in revised form May 5, 2014 